2. International humanitarian law: The underlying ideas, the Geneva Conventions, current tendencies in the development of the law of armed conflict.

3. Red Cross international meetings: the different types of meetings and their purpose, the role and work of a delegation, how to use simultaneous interpretation.

The faculty for the Seminar totalling sixteen persons was drawn from the International Committee of the Red Cross and the League of Red Cross Societies as well as from the academic world. Most of the sessions took place at the Henry Dunant Institute's new premises, while others were held at the ICRC and at the League.

At the close of the Seminar, the participants expressed the hope that the Institute would continue to organize seminars of this type and made a number of suggestions for improvements, one of which was that greater emphasis should be placed on the practical work of the Geneva institutions, with better opportunities to witness them in action.

The Seminar was held in English. A second Seminar, in French, is planned for next year and it will have the benefit of the experience gained on this first occasion.

\title{
A SYMPOSIUM AT THE HENRY DUNANT INSTITUTE
}

From 14 to 16 October 1974, a symposium entitled "The health care cost explosion: Which way now?" was held at the Henry Dunant Institute, in Geneva. The symposium-which was organized with the help of a grant from Pharma Information of Baslewas a fresh attempt to get to grips with the problem of dramatic increases in the costs of health care, which in most countries are absorbing an ever-increasing share of national resources. This problem troubles governments, citizens as patients and as taxpayers, 
the medical and allied professions, the pharmaceutical industry, and many others, including the Red Cross movement. For the first time on an international, voluntary level, a group of nearly 40 distinguished experts, representatives of these fields, was brought together in order to establish better communication and understanding among the parties involved and to try to gain new insight.

Papers were presented by : Dr. D. Flahault, of the World Health Organization; Prof. J.E.F. Hastings, University of Toronto ; Prof. Herbert E. Klarman, New York University ; Dr. Gordon MacLeod, University of Pittsburgh ; Mr. Robert J. Maxwell, McKinsey \& Company Inc., London; Mr. O. H. Nowotny, F. Hoffman-La Roche \& Co. Ltd., Basle ; Prof. Bror Rexed, Director General, the National Board of Health and Welfare, Sweden; Dr. Rolf Schlögell, Chairman of the Socio-Medical Affairs Committee of the World Medical Association, and Dr. P. Siderius, Secretary General, Ministry of Social Affairs and Health, Netherlands.

The Honorary President of the symposium was Dr. M.C. Candau, Director-General Emeritus of the World Health Organization. Sir George Godber, former Chief Medical Officer of the United Kingdom, was Chairman of the meeting, presiding over discussions which were often animated, sometimes controversial, but always in the end constructive.

In the general opinion of those taking part, the symposium was successful, and the new opportunity it provided for a dialogue was highly appreciated by the participants. The results of the symposium were numerous and enlightening; in due course they will be published in book form by the Henry Dunant Institute. 